\section{National Diabetes Month — November 2016}

November is National Diabetes Month. In the United States, 29 million persons have diabetes and 86 million adults have prediabetes, putting them at risk for developing type 2 diabetes, heart disease, and stroke (1). Approximately $28 \%$ of those with diabetes are undiagnosed (1), and $89 \%$ of those with prediabetes do not know they have it (2). Type 2 diabetes, which accounts for $90 \%-95 \%$ of all cases of diagnosed diabetes in the United States, can be prevented through lifestyle changes, such as weight loss, healthy eating, and increased physical activity $(1,3)$. Persons with diabetes can take steps to control the disease and prevent complications $(1,4)$.

CDC and partners play a crucial role in delaying or preventing type 2 diabetes, preventing diabetes complications, and improving the health and quality of life for all persons with diabetes. Good Health and Wellness in Indian Country is a CDC partnership (http://www.cdc.gov/chronicdisease/ pdf/ghwic-aag.pdf) that supports a coordinated and holistic approach to healthy living and chronic disease prevention for American Indians and Alaska Natives (AIAN). AIAN are twice as likely as non-Hispanic whites to have diagnosed diabetes (1); AIAN also experience higher death rates from diabetes and other chronic diseases (5).

The U.S. Diabetes Surveillance System provides a Diabetes Atlas, (http://gis.cdc.gov/grasp/diabetes/DiabetesAtlas.html), which allows users to view the latest state-level data and trends on any mobile device. The new Diabetes At A Glance fact sheet (http://www.cdc.gov/chronicdisease/resources/publications/ aag/pdf/2016/diabetes-aag.pdf) provides comprehensive information about diabetes, including risk factors, complications, and the financial costs of living with diabetes. More information about diabetes prevention and control is available at http:// www.cdc.gov/diabetes. Additional information about preventing diabetes complications is available at http://www.cdc.gov/ features/preventing-diabetes-complications/index.html.

\section{References}

1. CDC. National diabetes statistics report: estimates of diabetes and its burden in the United States, 2014. Atlanta, GA: US Department of Health and Human Services, CDC; 2014.

2. Li YF, Geiss LS, Burrows NR, Rolka DB, Albright A. Awareness of prediabetes-United States, 2005-2010. MMWR Morb Mortal Wkly Rep 2013;62:209-12.

3. Knowler WC, Barrett-Connor E, Fowler SE, et al.; Diabetes Prevention Program Research Group. Reduction in the incidence of type 2 diabetes with lifestyle intervention or metformin. N Engl J Med 2002;346:393-403. http://dx.doi.org/10.1056/NEJMoa012512
4. Venkat Narayan KM, Williams D, Gregg EW, Cowie C, eds. Diabetes public health: from data to policy. New York, NY: Oxford University Press; 2011.

5. Espey DK, Jim MA, Cobb N, et al. Leading causes of death and all-cause mortality in American Indians and Alaska Natives. Am J Public Health 2014;104(Suppl 3):S303-11 http://dx.doi.org/10.2105/AJPH.2013.301798

\section{Drowsy Driving Prevention Week - November 6-13, 2016}

Drowsy Driving Prevention Week, the National Sleep Foundation's annual campaign to educate the public about the hazards of driving while sleepy, will be observed November 6-13, 2016. A report released by the AAA Foundation for Traffic Safety in 2014 concluded that drowsy drivers were involved in an estimated $21 \%$ of fatal crashes, based on a nationally representative sample of motor vehicle crashes during 2009-2013 (1).

Drivers who work the night shift, work multiple jobs, or have irregular work schedules are at increased risk for motor vehicle crashes caused by drowsy driving (2). These groups are also more likely to report sleeping $<7$ hours per day (3): 70\% of night shift workers in the transportation and warehousing industry reported less than 7 hours of sleep per night (3), compared with $30 \%$ of all adult U.S. workers.

General information about drowsy driving is available from the National Sleep Foundation (http://drowsydriving.org/). Information for shift workers regarding how to improve their sleep and reduce their risk for drowsy driving also is available online (http://www.cdc.gov/niosh/topics/workschedules/).

\section{References}

1. Tefft BC. Prevalence of motor vehicle crashes involving drowsy drivers, United States, 2009-2013. Washington, DC: AAA Foundation for Traffic Safety; 2014. https://www.aaafoundation.org/sites/default/files/ AAAFoundation-DrowsyDriving-Nov2014.pdf

2. Stutts JC, Wilkins JW, Scott Osberg J, Vaughn BV. Driver risk factors for sleep-related crashes. Accid Anal Prev 2003;35:321-31. http://dx.doi. org/10.1016/S0001-4575(02)00007-6

3. CDC. Short sleep duration among workers-United States, 2010. MMWR Morb Mortal Wkly Rep 2012;61:281-5. 